\title{
The relationship between undergraduate nursing students' satisfaction about clinical learning environment and their competency self-efficacy
}

\author{
Azza Fathi Ibrahim*1, Thoraya Mohamed Abdelaziz², Dalal Talaat Akel ${ }^{3}$ \\ ${ }^{1}$ Nursing Education Departement, Faculity of Nursing, Alexandriea University, Egypt \\ ${ }^{2}$ Medical Surgical Department, Faculty of Nursing, Alexandria University, Egypt \\ ${ }^{3}$ Nursing Administration Department, Faculty of Nursing, The British University, Egypt
}

Received: April 7, 2019

DOI: $10.5430 /$ jnep.v9n11p92
Accepted: August 4, 2019

Online Published: September 3, 2019

\begin{abstract}
Competency self-efficacy (CSE) in clinical nursing practice is necessitated to be attained by the undergraduate nursing students. It is a significant indicator of the work's acceptance and commitment to nursing roles. Self-efficacy in nursing experience enhances nursing student's abilities to achieve the clinical tasks independently, mainly in wide range field of care like Medical-Surgical Nursing. Some factors are affecting competency self-efficacy in the clinical nursing practice; the most evident factor is the nursing student's impressions with their clinical learning environment (CLE). In the light of educational preparation for nursing undergraduates, the Faculties of Nursing emphasize to preserve a high quality of clinical learning environment for clinical nursing essentials. The clinical learning environment has an apparent function in building up students' confidence, and competency selfefficacy, particularly, during clinical skills achievement. The current paper aimed to determine undergraduate nursing student's satisfaction about the clinical learning environment and their competency self-efficacy, and then investigate the relationship between both variables. Thus, the study conducted through a descriptive, correlative research design with all nursing students who enrolled in third and fourth academic semesters (second year) during their clinical training in Medical-Surgical Nursing course, Faculty of Nursing, Alexandria University, Egypt. A triple-section questionnaire was used for data collection: First; nursing student's sociodemographic profile, Second: Clinical Learning Environment Inventory (CLEI) which was constructed by Chan in 2002. Third: Nursing Competency Self Efficacy Scale (CSES) which was developed by Kennedy in 2013. The results showed that the undergraduate nursing students at Medical-Surgical training, Faculty of Nursing, Alexandria University, have a high satisfaction level about the clinical learning environment concerning all components of the clinical placement. As well, they have a high competency self-efficacy level in all nursing activities and tasks in the clinical training. Further, there is an obvious parallel correlation between nursing student's satisfaction about clinical learning environment and their competency self-efficacy which is significant. Conclusion \& Recommendations: Adequate and planned arrangements should be settled in the nursing curricula for the nursing clinical training setting. Too, the clinical instructors should encourage students' trials to do difficult nursing tasks in a successful manner which tends to increase the student's competency self-efficacy. Further researches are required to investigate the factors affecting clinical learning environment satisfaction and competency self-efficacy among nursing students in their clinical placement. Additionally, another research is necessary about; developing an educational program about student's competency self-efficacy to guide nursing instructors in clinical training.
\end{abstract}

Key Words: Competency self-efficacy, Clinical learning environment, Medical-surgical nursing, Nursing students, Nursing education

*Correspondence: Azza Fathi Ibrahim; Email: azza_fathy2008@yahoo.com; Address: Nursing Education Departement, Faculity of Nursing, Alexandriea University, Egypt. 


\section{INTRODUCTION}

The place of the clinical nursing experience must be a support area for pedagogically clinical interaction. Nurse educators should observe, maintain and arrange the constructive positive clinical teaching-learning environment to enhance and develop professional nursing skills' acquisition. In the nursing discipline, the quality of the clinical learning environment affects positively and significantly student's satisfaction and performance. Accordingly, nursing student's clinical competency is dependent on their satisfaction with the clinical learning surroundings. ${ }^{[1,2]}$

European Parliament Directive in 2013 advised tailoring 50\% of nursing curriculum time to be for clinical training to allow the graduates attaining the required clinical competencies. These competencies are paramount of the nursing practice at all. Therefore, the clinical learning environment physically and psychologically should be supportive and helpful for nursing students. It is the backbone of nursing pedagogy to equip the undergraduates with decision making and clinical judgment skills. ${ }^{[2,3]}$

Clinical training in Medical-Surgical Nursing field is the key elements of the advancement of the nursing profession paradigm. The nursing field is a practical discipline. The empirical nursing experiences in undergraduate clinical training are essential and central activities in nursing education and Medical-Surgical Nursing field. Clinical learning can be defined as the education in clinical settings including the application of scientific and academic knowledge and skills, plus attitudes and values. As well, it is the carrying out of nursing interventions in a clinical real environment with patients. So, it is considering a shift from theoretical learning and lab simulation to actual nursing practice. Throughout hands-on activities with the environments and clients, nursing students usually gain competencies and skills. ${ }^{[4,5]}$ Under the direction of the Nursing Faculty, the nursing educators in Medical-Surgical Nursing branch have an essential role, to instruct, guide and support the nursing students in their clinical work to be equipped for the actual clinical environment. The nursing instructor has to maintain patient's and student's safety and prepare the clinical placement. The instructor role in clinical learning environment preparation is a significant factor that can hinder or facilitate the student's clinical experiences. The level of students' dependability in practice is determined by the quality of their clinical preparations, especially in Medical-Surgical Nursing department as a cornerstone nursing clinical area. ${ }^{[6-10]}$

Medical-surgical nursing is a crucial nursing area of expertise focused on providing nursing practice to adult patients in wide-ranging clinical placements with various types of diseases. Medical-surgical nursing is a particular major nursing area in both knowledge and practice. Medical-Surgical Nurses can give nursing care with acute or chronic, medical or surgical, on admission or in recovery and discharge phase of the patient's illness. They are competent coordinators and managers in any site of the hospital. All nursing responsibilities can be carried out by Medical-Surgical Nurses. The main exceptional role of Medical-Surgical Nurse is that they can deal with all body systems, many of illnesses, various body sufferings and patient's complaints. Therefore, in such a department, nursing students need advanced cognitive skills, clinical judgment, and problem-solving skills. So, the clinical learning environment has essential preparations for nursing students, in such informative department. ${ }^{[8-12]}$

Clinical learning environment groundwork involves many challenges, difficulties, and overwhelming work, such as tension and anxiety among nursing students during clinical training. Further, nursing students in clinical work have numerous duties, responsibilities, and emotional burdens. Consequently, preparing and equipping of clinical learning environment is an academic necessary to help the nursing students adjusting in their clinical training, and be satisfied with their learning, in a vital area such as Medical-Surgical Nursing. ${ }^{[10,12-14]}$ Clinical learning environment consists of energies and factors in the experimental location that influences nursing students' accomplishment. The building blocks of it may be the arrangement, agency, building, and emotional climate. By another word, it refers to "a multidimensional entity that directly affects the outcomes of students' clinical placement". It involves hospitals, healthcare centers, rehabilitation centers, home nursing care, and practical lab. Clinical learning environment embodied in four attributes: structural space (equipments and supplies for care), psychosocial aspect (communications, interactions, attitudes such anxiety and satisfaction), organizational culture (staff social climate, rules and policies, and leadership) and educational elements (instructors, guidance, method of teaching, active role of the nursing student, and educational pan or materials). All such attributes in the clinical learning environment are dependent on the availability of patients with various diagnoses and treatment regimens that allow the nursing students to apply their knowledge and gain the needed essential nursing skills. So, nursing student's satisfaction with their clinical learning environment is necessary. Worldwide, a lot of references found that unconstructive clinical learning environment can hinder the attainment of learning targets, delay gaining of skills, attrition, dissatisfaction among nursing students, mainly, in Medical-Surgical Nursing practice. ${ }^{[14-18]}$ Nursing student's satisfaction with the clinical learning environment is noteworthy. It builds a grand motive and essential power 
among the nursing students to accept their job roles, apply nursing skills competently and carry out their responsibilities accurately and proficiently. The superior quality of clinical learning environment is an obvious pointer to nursing student's strong self-efficacy in performance and their high quality of clinical training outcomes. ${ }^{[1,11,19,20]}$

The competent self-efficacy defines as the faith of the person in own capabilities to do the work missions and attain the desired outcomes. Nursing student's competence self-efficacy is a highly necessitate goal in clinical learning that of course, will lead to successful training and thus positive nursing career. Competency self-efficacy among nurses is parallel with academic improvement, professional skill achievement, decreasing patient's risks, and better healthcare results. ${ }^{[21-23]}$ In the past century, Albert Bandera in 1986 and 1998 defined the self-efficacy as an individual's beliefs about his/her potentials to produce designated levels of performance that influence over events and maintain life's stability. As well, self-efficacy refers to a person's attitudes, abilities, and cognitive skills that comprise what is known as the self-system. Self-efficacy is determining how people think and behave. Competency self-efficacy is a key psychological construct concerning how people adapt to environments where new skills are developed. ${ }^{[24-27]}$ So, in Medical-Surgical Nursing clinical training, students with competency self-efficacy have a high assurance in their capabilities to complete difficult and various tasks and overcome any work challenge. Nursing students will automatic mastering the skills to face problems and solve them, rather than avoidance of them. In contrast, nursing students who doubt with their capabilities shy away from difficult tasks and cannot reach their targets. They have low aspirations and a weak commitment to the goals they choose to pursue. There are many factors should be tailored to encourage competency self-efficacy between nursing undergraduates, the first is their satisfaction with clinical training placement. In Egypt, Al Sebae et al., in 2017, reported that nurse educators have to choose and prepare constructive clinical learning environment to encourage nursing student's competency self-efficacy in their performance. ${ }^{[25,26,28]}$ All efforts should be done to equip our nursing students with competency self-efficacy; the main effort is tailoring a helpful clinical learning environment.

\subsection{The significance of the study}

Clinical learning environment planning is a fundamental and curial part in Medical-Surgical Nursing curricula. Nursing student's satisfaction with the clinical learning environment may be beneficial to be assessed to ensure student's competency self-efficacy in clinical nursing training. As well, nursing student's competency self-efficacy may be a pointer to their clinical learning environment satisfaction. But, till now, there are no studies to investigate the relationship between those variables among nursing students, particularly, in Medical-Surgical Nursing area in Egypt. Although in a developmental country such as Egypt, there are limited resources, limited nursing staff, and monetary sufferings, there is necessitating assessing the levels of both clinical learning environment satisfaction and competency self-efficacy among nursing students, mainly in an indispensable field namely; Medical-Surgical Nursing field and then, investigating their association which is an exceptional trial. This investigation will help to improve the nursing student's self-efficacy in their practice by fitting the clinical learning environment' attributes.

\subsection{Research questions}

- What is the satisfaction level of the clinical learning environment among undergraduate nursing students, Medical-Surgical Nursing course, Faculty of Nursing, Alexandria University, Egypt?

- What is the competency self-efficacy level among undergraduate nursing students, Medical-Surgical Nursing course, Faculty of Nursing, Alexandria University, Egypt?

- What is the correlation between satisfaction about the clinical learning environment and competency self-efficacy among undergraduate nursing students, Medical-Surgical Nursing course, Faculty of Nursing, Alexandria University, Egypt?

\subsection{Research hypothesis}

There is a significant parallel relationship between satisfaction about clinical learning environment and competency self-efficacy among undergraduate nursing students, MedicalSurgical Nursing course, Faculty of Nursing, Alexandria University, Egypt.

\section{Material \& Method}

\subsection{Research design}

The recent study conducted through a descriptive correlation research design to identify and determine the levels and association between satisfaction about the clinical learning environment and competency self-efficacy among undergraduate nursing students.

\subsection{Setting \& subjects}

Study participants consisted of all nursing students who enrolled in third and fourth academic semesters (second academic year) during their clinical training in Medical-Surgical Nursing course, Faculty of Nursing, Alexandria University, 
Egypt. Three hundred thirty (330) nursing students agreed to participate in the study, out of 390 (38 from the third semester and 292 from the fourth semester). They obtained their clinical training in Al Miri, Nariman and Al Mawasah Hospitals in Alexandria, Egypt. The pilot sample and the students, who refused participation in the study, were excluded from the study sample.

\subsection{Study instruments}

A triple-section questionnaire was used for data gathering:

First section: Nursing student's Sociodemographic profile sheet.

Second section: Clinical Learning Environment Inventory (CLEI). It was developed by Chan in 2002 and 2003. ${ }^{[29,30]}$ It involves forty-two statements with four points Likert scale. This instrument contains two editions; "actual" and "preferred" ones. The actual version asks the students to rate the forty-two statements about the definite actual and real clinical environment while the preferred version asks the students to rate the forty-two statements about their preference, ideal and wishes that they hope to be present in the clinical placement. The inventory includes six scales: Personalization (focuses on student's chances to deal with the instructor for students favor), Student Involvement (the degree of active participation of the students in clinical activities), Satisfaction (the degree of student's gratification from clinical environment), Task Orientation (the degree of ward activities clarity and organization), Teaching Innovation (the degree of innovation and attractiveness in the instructor teaching plans that involves clinical experiences, tutorial methodology, interaction activities, and patient allowances), and Individualization (the degree of student's chances to make decisions and their different assessment consistent with skills aptitude or attention). The four-point rating scale was ranged as: Strongly Agree $=4$, Agree $=3$, Disagree $=2$ and Strongly Disagree $=1$, whereas, the negative item was scored reversely. This scale was modified by the researchers and specialized statistician to include five points scale, not four, by adding neutral in between agree and disagree response. Therefore, the scoring became: from $1 \geq 40$ considered student's dissatisfaction, from $40 \geq 80$ denoted student's neutral response, and from $80 \geq 120$ signified student's satisfaction. The scale' range with five points allowed a valid comparison between satisfaction about the clinical learning environment and competency self-efficacy levels. Chan in $2003^{[30]}$ documented inter-item reliability (using Cronbach's alpha statistical program) of 0.73 to 0.84 for the actual edition and 0.66 to 0.80 for the preferred edition of CLEI. The content validity was checked and demonstrated agreed content and face validity by the researchers. The current study used the actual edition only

Published by Sciedu Press of the CLEI.

Third section: Nursing Competency Self Efficacy Scale (NCSES). It was developed by Kennedy in $2013^{[31]}$ to assess senior nursing student's self-efficacy for competent nursing practice. This tool contains thirty-two statements about clinical performance with nine points Likert scale. It was checked by Kennedy for reliability (internal consistency reliability, test-retest stability reliability) that showed accepted value. Also, it was checked for validity (content validity, construct validity and contrasting group validity). Its Likert scale ranged between $1=$ certain cannot do to $9=$ certain can do. This scale was adjusted by the researchers and specialized statistician to include only five points scale, not nine. Consequently, the scoring established to be: from $1 \geq 53$ indicated student's low level of competency self-efficacy, from $53 \geq 106$ represented student's moderate level of competency self-efficacy, and from $106 \geq 160$ showed student's high level of competency self-efficacy. The scale' range with five points allowed a valid comparison between satisfaction level about clinical learning environment and competency self-efficacy level.

Section two and three were rechecked for content validity by a jury of four experts in nursing education, Medical-Surgical Nursing, Nursing Administration, and Psychiatric Nursing fields to establish its feasibility and applicability and essential modifications were done. As well, both sections were statistically investigated for reliability using Cronbach's alpha statistical program test with the pilot sample sheets which revealed accepted values in between 0.73 and 0.82 for both sections.

\subsection{Ethical considerations}

Written endorsements from ethical committee and postgraduation department of the Faculty of Nursing, Alexandria University, Egypt, were taken. Written informed consents, as documents of nursing student's voluntary participation before filling the study tools, were prepared and given to the nursing students. The informed consents involved the purpose of the study and all participants' rights. It entailed instructions to participants to participate or withdraw at any time with no penalties in their evaluation grading. With their signed consent, they filled the study instrument in the attendance of the researchers to explain any vague items in the study tool. Anonymity was established by instructing the students to avoid writing their names on the study tool.

\subsection{Pilot study}

A pilot study was accomplished on thirty-five nursing students who were picked by chance randomly and separately from the study sample. A pilot was conducted to check tool 
simplicity, practicability, and understandability among the nursing students. The study tool was copied and distributed amongst the students in their clinical placement. The data collection was done in March and April 2019.

\subsection{Statistical analysis}

Data was supplied, coded, revised and investigated using the PC with Statistical Packages for Social Science (SPSS 20) and Windows Version 7.0. The selected level of significance was $p$ level $<.01$. Descriptive statistics were done using numbers, percentage, arithmetic mean and standard deviation. Then, Univariate analyses were performed by using of the Spearman's rho statistical test to quantify the strength of the association between the study variables.

\section{RESUltS}

Table 1 illustrates the profile of the undergraduate nursing students who enrolled in the Medical-Surgical Nursing course (clinical training part). Nearly, two-thirds of them (61.2\%) are in the age of 17 to 20 years old. Approximately, the same percent $(66.4 \%)$ are females and about all of them $(96 \%)$ are single. More than one half of them $(57 \%)$ are coming from the urban region of Egypt.

Table 1. Participants profile

\begin{tabular}{|c|c|c|}
\hline \multirow{2}{*}{ Socio-demographic data } & \multicolumn{2}{|c|}{$(n=330)$} \\
\hline & No. & $\%$ \\
\hline \multicolumn{3}{|l|}{ Age } \\
\hline $17 \leq 20$ & 202 & 61.2 \\
\hline $20 \leq 23$ & 96 & 29.1 \\
\hline $23 \leq 26$ & 32 & 9.7 \\
\hline \multicolumn{3}{|l|}{ Gender } \\
\hline Female & 219 & 66.4 \\
\hline Male & 111 & 33.6 \\
\hline \multicolumn{3}{|l|}{ Maritalstatus } \\
\hline Single & 315 & 95.4 \\
\hline Married & 13 & 4 \\
\hline Divorced & 2 & 0.6 \\
\hline Others (widow) & 0 & 0.0 \\
\hline \multicolumn{3}{|l|}{ Residence } \\
\hline Urban & 188 & 57 \\
\hline Rural & 142 & 43 \\
\hline \multicolumn{3}{|l|}{ Academic semester } \\
\hline Third semester & 38 & 11.5 \\
\hline Fourth semester & 292 & 88.5 \\
\hline \multicolumn{3}{|c|}{ Qualification before joining nursing college } \\
\hline Secondary school & 280 & 84.8 \\
\hline Technical health institute & 41 & 12.4 \\
\hline Bachelor from other faculty & 9 & 2.7 \\
\hline \multicolumn{3}{|c|}{ Experience clinical work problems } \\
\hline Usually & 89 & 27 \\
\hline Often & 111 & 33.6 \\
\hline Sometimes & 87 & 26.4 \\
\hline Rarely & 43 & 13 \\
\hline
\end{tabular}

The majority of the nursing students $(88.5 \%)$ is in the fourth academic semester and around the same percent $(84.8 \%)$ are joining the faculty of nursing after secondary school. Additionally, about two thirds $(27 \%, 33.6 \%)$ of the subjects are usually and often faced clinical work problems in their clinical training.

Concerning the answer to the study question one, Table 2 shows that, approximately, all of the nursing students $(94.2 \%$, $92.1 \%$ ) satisfied regarding their involvement and task orientation in the clinical learning environment. While about two-thirds of the study subjects $(64.8 \%, 61 \%)$ satisfied regarding personalization and individualization items in the clinical learning environment. Moreover, more than one-half of nursing students $(59.4 \%, 57.6 \%)$ are satisfied with the learning environment and teaching innovation in it. On the whole, the largest part of undergraduate nursing students $(71.5 \%)$ satisfied with all components of the clinical learning environment.

As well, and for more clarification concerning the answer of the study question one, Table 3 presents the nursing student's responses within the five-point Likert scale (CLEI) in a form of Mean \& Standard deviation. The nursing students have high mean scores $(4.7,4.6)$ in the items "involvement and task orientation" in CLEI which indicates their high agreement and satisfaction. While in the items of "Personalization, Learning environment satisfaction and Individualization", the nursing students documented Mean $\geq 3$ which denotes their accepted level of satisfaction. Regarding teaching innovation, the subjects have Mean $=2.9$ that signifies their marginal satisfaction as regards this item of CLEI. In general, the undergraduate nursing students got mean $=3.6$ which indicates their high satisfaction level with all clinical learning environment components.

Pertaining to the answer of the study question two, Table 4 illustrates that almost all of the study subjects $(96.7 \%$, $95.2 \%, 97.6 \%$, and $98.8 \%$ ), respectively, in relation to "Broad Knowledge, Interpret Data and Provision of Multiple Interventions" perceived high competency self-efficacy level. Whereas, about one-third of the nursing students $30.3 \%$, $33.6 \%$, and $35.5 \%$ ) correspondingly, regarding, "Conflict Resolution, Promotion Outcomes, and Ethical Dilemmas" have moderate competency self-efficacy level. But, in the other scale items; there are minimal percents of the subjects reported moderate and low competency self-efficacy levels. Generally, $81.2 \%$ of the study participants perceived high competency self-efficacy level for all skills of competency self-efficacy scale. 
Table 2. Clinical learning environment satisfaction level among undergraduate nursing students as presented by number and percentages, mean and standard deviation

\begin{tabular}{|c|c|c|}
\hline \multirow{2}{*}{$\begin{array}{l}\text { Clinical learning environment inventory } \\
\text { components and satisfaction level }\end{array}$} & \multicolumn{2}{|c|}{$\begin{array}{l}\text { Nursing students } \\
(\mathrm{n}=330)\end{array}$} \\
\hline & No. & $\%$ \\
\hline \multicolumn{3}{|l|}{$\begin{array}{l}\text { Personalization (student's chances to deal } \\
\text { with the instructor for students favor) }\end{array}$} \\
\hline Satisfied & 214 & 64.8 \\
\hline Neutral & 89 & 27 \\
\hline Dissatisfied & 27 & 8.2 \\
\hline \multicolumn{3}{|l|}{$\begin{array}{l}\text { Student Involvement (the degree of } \\
\text { student's active participation in clinical } \\
\text { activities) }\end{array}$} \\
\hline Satisfied & 311 & 94.2 \\
\hline Neutral & 12 & 3.6 \\
\hline Dissatisfied & 7 & 2.2 \\
\hline \multicolumn{3}{|l|}{$\begin{array}{l}\text { Learning environment satisfaction (the } \\
\text { degree of student's gratification for the } \\
\text { clinical environment) }\end{array}$} \\
\hline Satisfied & 196 & 59.4 \\
\hline Neutral & 77 & 23.3 \\
\hline Dissatisfied & 57 & 17.3 \\
\hline \multicolumn{3}{|l|}{$\begin{array}{l}\text { Task Orientation (the degree of ward } \\
\text { activities clarity and organization) }\end{array}$} \\
\hline Satisfied & 304 & 92.1 \\
\hline Neutral & 7 & 2.1 \\
\hline Dissatisfied & 19 & 5.8 \\
\hline \multicolumn{3}{|l|}{$\begin{array}{l}\text { Teaching Innovation (the degree of } \\
\text { innovation and attractiveness in the } \\
\text { instructor teaching plans) }\end{array}$} \\
\hline Satisfied & 190 & 57.6 \\
\hline Neutral & 66 & 20 \\
\hline Dissatisfied & 74 & 22.4 \\
\hline \multicolumn{3}{|l|}{$\begin{array}{l}\text { Individualization (the degree of student's } \\
\text { chances to make decisions and experience } \\
\text { skills) }\end{array}$} \\
\hline Satisfied & 201 & 61 \\
\hline Neutral & 88 & 26.6 \\
\hline Dissatisfied & 41 & 12.4 \\
\hline \multicolumn{3}{|l|}{ Total scores } \\
\hline Satisfied & 236 & 71.5 \\
\hline Neutral & 56 & 17 \\
\hline Dissatisfied & 38 & 11.5 \\
\hline
\end{tabular}

Also, for more illustrations, as regards the answer to the study question two, Table 5 demonstrates that the majority of nursing students perceived high competency self-efficacy level, because, all mean scores are $\geq 2.7$. Concerning "Broad Knowledge, Interpret Data and Provision of Multiple Interventions" the nursing students got mean scores $\geq 4.7$ which signifies that they have the high level of competency selfefficacy in those items. While, the subjects got mean scores (2.7, 2.8 and 2.7) respectively in items "Conflict Resolution,
Promotion Outcomes, and Ethical Dilemmas" which indicates that the nursing students perceived accepted the level of competency self-efficacy in such items. On the whole and in all scale items, the nursing students obtain 4.1 mean score which refers to their high level of competency self-efficacy.

Table 3. Clinical learning environment satisfaction among undergraduate nursing students as presented by the mean and standard deviation

\begin{tabular}{|c|c|}
\hline \multirow{2}{*}{$\begin{array}{l}\text { Clinical learning environment } \\
\text { inventory components }\end{array}$} & Nursing students $(\mathrm{n}=330)$ \\
\hline & $\begin{array}{l}\text { Mean } \pm \text { SD } \\
\text { (5 points Likert scale) }\end{array}$ \\
\hline Personalization & $3.2 \pm 1.88$ \\
\hline Student Involvement & $4.7 \pm 0.87$ \\
\hline Learning environment satisfaction & $3.00 \pm 1.57$ \\
\hline Task Orientation & $4.6 \pm 0.92$ \\
\hline Teaching Innovation & $2.9 \pm 1.04$ \\
\hline Individualization & $3.00 \pm 1.33$ \\
\hline Total & $3.6 \pm 0.96$ \\
\hline
\end{tabular}

Consistent with the answer of the study question three, the data in Table 6 clarifies that the correspondence and association of satisfaction about the clinical learning environment and competency self-efficacy levels between nursing students. There is an obvious parallel proportion between both study variables in which Spearman's rho association test $r=0.716$. The maximum percentage of nursing students $(60.3 \%)$, who perceived a high satisfaction level about the clinical learning environment, is almost, the same peak percentage of nursing students who reported high competency self-efficacy level. This result is fitting the research hypothesis. Following the current data in Table 6, the study variables that under investigation show the congruency of the nursing student's percent that is representing high satisfaction level about the clinical learning environment (60.3\%), which is the identical percent obtained by the students who have a high competency selfefficacy level. In contrast, there are minimal percents of the nursing students who perceived dissatisfaction or neutral levels about the clinical learning environment and also, for who have low or moderate levels in competency self-efficacy. The equivalent and parallel correlation coefficient among satisfaction about the clinical learning environment and competency self-efficacy levels among nursing students are significant.

Figure 1 illustrates a comparison between the levels of satisfaction about the clinical learning environment and competency self-efficacy as perceived by study subjects. (Dissatisfied, Neutral and Satisfied) are the rating of satisfaction level about the clinical learning environment which reported by nursing students. It matches the same bar-chart, with (Low, Moderate and High) that are the rating for competency 
self-efficacy level. A parallel correlation between nursing student's satisfaction about the clinical learning environment and their competency self-efficacy levels is observed. This is because the chart shows that the students who reported high scores in satisfaction about the clinical learning envi- ronment have high scores in competency self-efficacy and vice-versa. Consequently, a stronger positive correlation is observed between the study variables as perceived by the nursing students.

Table 4. Competency Self Efficacy level among undergraduate nursing students as presented by number $\&$ percentages

\begin{tabular}{|c|c|c|c|c|c|c|c|}
\hline \multirow{4}{*}{\multicolumn{2}{|c|}{$\begin{array}{l}\text { Competency Self Efficacy Scale } \\
\text { components }\end{array}$}} & \multirow{2}{*}{\multicolumn{6}{|c|}{$\begin{array}{l}\text { Nursing students }(n=330) \\
\text { Competency Self Efficacy perceived level }\end{array}$}} \\
\hline & & & & & & & \\
\hline & & \multicolumn{2}{|c|}{$\begin{array}{l}\text { LOW COMPETENCY } \\
\text { SELF-EFFICACY }\end{array}$} & \multicolumn{2}{|c|}{$\begin{array}{l}\text { Moderate } \\
\text { COMPETENCY } \\
\text { SELF-EFFICACY }\end{array}$} & \multicolumn{2}{|c|}{$\begin{array}{l}\text { High } \\
\text { COMPETENCY } \\
\text { SELF-EFFICACY }\end{array}$} \\
\hline & & & $\%$ & \multirow{2}{*}{$\begin{array}{l}\text { No. } \\
26\end{array}$} & \multirow{2}{*}{$\begin{array}{l}\% \\
7.9\end{array}$} & \multirow{2}{*}{$\begin{array}{l}\text { No. } \\
296\end{array}$} & \multirow{2}{*}{$\begin{array}{l}\% \\
89.7\end{array}$} \\
\hline 1) & Code of Ethics & & & & & & \\
\hline 2) & Practice in Absence of agency policy & 23 & 6.9 & 40 & 12.1 & 267 & 80.9 \\
\hline 3) & Conflict Resolution & 53 & 16.1 & 100 & 30.3 & 177 & 53.6 \\
\hline 4) & Challenge Orders of health team & 13 & 3.9 & 55 & 16.7 & 226 & 68.5 \\
\hline 5) & Near Misbehavior in Care & 4 & 1.2 & 61 & 18.5 & 265 & 80.3 \\
\hline 6) & Broad Knowledge & 3 & 0.9 & 8 & 2.4 & 319 & 96.7 \\
\hline 7) & Awareness of global Health Issues & 10 & 3.03 & 45 & 13.6 & 275 & 83.3 \\
\hline 8) & Identify Research point & 27 & 8.2 & 92 & 27.9 & 211 & 63.9 \\
\hline 9) & Using of assessment tools & 7 & 2.1 & 46 & 13.9 & 277 & 83.9 \\
\hline 10) & Interpret Data & 6 & 1.8 & 10 & 3.03 & 314 & 95.2 \\
\hline 11) & Awareness of Health Inequities & 24 & 7.3 & 50 & 15.2 & 256 & 77.6 \\
\hline 12) & Assessments Timely & 13 & 3.9 & 38 & 11.5 & 279 & 84.5 \\
\hline 13) & Critical Thinking & 8 & 2.4 & 55 & 16.7 & 267 & 80.9 \\
\hline 14) & Anticipate Problems & 10 & 3.03 & 62 & 18.8 & 258 & 78.2 \\
\hline 15) & Consult Team & 11 & 3.3 & 30 & 9.1 & 289 & 87.6 \\
\hline 16) & Multiple Interventions & 2 & 0.6 & 6 & 1.8 & 322 & 97.6 \\
\hline 17) & Assist in Rapid Change & 4 & 1.2 & 99 & 30 & 227 & 68.8 \\
\hline 18) & Promotion Outcomes & 32 & 9.7 & 111 & 33.6 & 187 & 56.7 \\
\hline 19) & Provision care for Chronic Ongoing & 9 & 2.7 & 25 & 7.6 & 296 & 89.7 \\
\hline 20) & Meet client's Physiological Needs & 6 & 1.8 & 36 & 10.9 & 288 & 87.3 \\
\hline 21) & Using Safety Principles & 1 & 0.3 & 3 & 0.9 & 326 & 98.8 \\
\hline 22) & Therapeutic Intervention. & 12 & 3.6 & 51 & 15.5 & 267 & 80.9 \\
\hline 23) & Prepare Diag. Treat. & 8 & 2.4 & 44 & 13.3 & 278 & 84.2 \\
\hline 24) & Hospice Palliative care & 10 & 3.03 & 41 & 12.4 & 279 & 84.5 \\
\hline 25) & Evidence Informed decisions & 11 & 3.3 & 52 & 15.8 & 267 & 80.9 \\
\hline 26) & Report Evaluation & 10 & 3.03 & 62 & 18.8 & 258 & 78.2 \\
\hline 27) & Understanding Informed Consent & 15 & 4.5 & 22 & 6.7 & 293 & 88.8 \\
\hline 28) & Address Ethical Dilemmas & 34 & 10.3 & 117 & 35.5 & 179 & 54.2 \\
\hline 29) & Advocate for Clients & 8 & 2.4 & 24 & 7.3 & 298 & 90.3 \\
\hline 30) & Demonstrate Respect & 11 & 3.3 & 32 & 9.7 & 287 & 87 \\
\hline 31) & Take actions in Abusive Situations & 18 & 5.5 & 56 & 16.9 & 256 & 77.6 \\
\hline 32) & Fitness to Practice & 13 & 3.9 & 23 & 6.9 & 294 & 89.1 \\
\hline Tota & & 14 & 4.3 & 48 & 14.5 & 268 & 81.2 \\
\hline
\end{tabular}




\section{Discussion}

Undergraduate nursing students are the backbone of the nursing profession. They should be equipped with different nursing skills through their clinical training, essentially in an important area such as Medical-Surgical Nursing. This experience requires adequate preparations in the clinical placement and the nursing students themselves. The clinical nursing work in such field is full of tension, challenges, and reality shock. But, they are required to have competent self-efficacy in performing the nursing practice. Unfortunately, there is little research evidence about "the relationship between undergraduate nursing student's satisfaction about the clinical learning environment and their competency self-efficacy". The current variables are essential issues that should be investigated among this group of students and in a vital job such as Medical-Surgical Nursing. According to the present results, as regards the subject's profile, most nursing students are females and in their late period of the second decade. The male students in nursing career are still in minimal proportion. Congruent with this result, In Alexandria, Egypt, Abd El-Halem et al., in 2011, highlighted that male students have many chances in nursing work before and after graduation, but they are still in a few quantities in the nursing field. ${ }^{[10,12,32]}$ In the same line and also, in Egypt, Gaber, and Mostafa in 2013 found that the nursing profession is a critical job in the community, however, there is a serious deficiency in the nursing workforce, particularly among males. ${ }^{[33]}$

A noteworthy part of the study subjects is from urban districts in Egypt areas. This can be because; it is an obligation on the students who have the nearest residence to the faculty to join it according to their geographical distribution in Egypt. While the students in rural places have to join the nearest college to their residence, so, they are representing the little number in the faculty of nursing, Alexandria University. ${ }^{[33,34]}$
Table 5. Competency Self Efficacy level among undergraduate nursing students as presented by the mean and standard deviation

\begin{tabular}{|c|c|c|}
\hline \multicolumn{2}{|c|}{$\begin{array}{l}\text { Competency Self Efficacy Scale } \\
\text { components }\end{array}$} & \multirow{2}{*}{$\begin{array}{l}\begin{array}{l}\text { Nursing students } \\
(\mathbf{n}=\mathbf{3 3 0})\end{array} \\
\text { Mean } \pm \text { SD } \\
(5 \text { points Likert scale) }\end{array}$} \\
\hline 1) & Code of Ethics & \\
\hline 2) & Practice in Absence of agency policy & $4.04 \pm 0.87$ \\
\hline 3) & Conflict Resolution & $2.7 \pm 1.54$ \\
\hline 4) & Challenge Orders of the health team & $3.4 \pm 1.33$ \\
\hline 5) & Near Misbehavior in Care & $4.01 \pm 1.02$ \\
\hline 6) & Broad Knowledge & $4.8 \pm 0.87$ \\
\hline 7) & Awareness of global Health Issues & $4.5 \pm 0.98$ \\
\hline 8) & Identify Research point & $3.2 \pm 1.14$ \\
\hline 9) & Using assessment tools & $4.2 \pm 0.94$ \\
\hline 10) & Interpret Data & $4.7 \pm 0.87$ \\
\hline 11) & Awareness of Health Inequities & $3.88 \pm 1.23$ \\
\hline 12) & Assessments Timely & $4.2 \pm 0.92$ \\
\hline 13) & Critical Thinking & $4.04 \pm 0.78$ \\
\hline 14) & Anticipate Problems & $3.9 \pm 0.96$ \\
\hline & Consult Team & $4.4 \pm 0.89$ \\
\hline 16) & Multiple Interventions & $4.9 \pm 0.91$ \\
\hline 17) & Assist in Rapid Change & $3.4 \pm 1.08$ \\
\hline 18) & Promotion Outcomes & $2.8 \pm 1.54$ \\
\hline 19) & Provision care for Chronic Ongoing & $4.5 \pm 0.87$ \\
\hline & Meet client's Physiological Needs & $4.4 \pm 0.93$ \\
\hline 21) & Using Safety Principles & $4.9 \pm 0.75$ \\
\hline 22) & Therapeutic Intervention. & $4.04 \pm 0.96$ \\
\hline 23) & Prepare Diag. Treat. & $4.2 \pm 1.04$ \\
\hline 24) & Hospice Palliative care & $4.2 \pm 0.88$ \\
\hline 25) & Evidence-Informed decisions & $4.04 \pm 0.93$ \\
\hline 26) & Report Evaluation & $3.9 \pm 1.05$ \\
\hline & Understanding Informed Consent & $4.4 \pm 0.85$ \\
\hline 28) & Address Ethical Dilemmas & $2.7 \pm 1.76$ \\
\hline & Advocate for Clients & $4.5 \pm 0.87$ \\
\hline & Demonstrate Respect & $4.3 \pm 0.68$ \\
\hline & Take actions in Abusive Situations & $3.9 \pm 0.97$ \\
\hline & Fitness to Practice & $4.5 \pm 0.91$ \\
\hline Tota & & $4.1 \pm 0.95$ \\
\hline
\end{tabular}

Table 6. Correlation coefficient between satisfaction about the clinical learning environment and competency self-efficacy levels among undergraduate nursing students as presented by number, percentage and Spearman's rho assessment

\begin{tabular}{|c|c|c|c|c|c|c|c|c|}
\hline \multirow{3}{*}{ Correlation } & & \multicolumn{6}{|c|}{ Clinical learning environment satisfaction (CLES) $n=330$} & \multirow{3}{*}{$\begin{array}{l}\text { Statistical } \\
\text { test }\end{array}$} \\
\hline & & \multicolumn{2}{|c|}{ Dissatisfied $(n=38)$} & \multicolumn{2}{|c|}{ Neutral $(n=56)$} & \multicolumn{2}{|c|}{ Satisfied $(n=236)$} & \\
\hline & & No. & $\%$ & No. & $\%$ & No. & $\%$ & \\
\hline \multirow{3}{*}{$\begin{array}{l}\text { Competency } \\
\text { self-efficacy } \\
\text { (CSE) N = } 330\end{array}$} & Low $(n=14)$ & 3 & 0.9 & 2 & 0.6 & 9 & 2.7 & \multirow{3}{*}{$\begin{array}{l}r=0.776^{* *} \\
p=.000\end{array}$} \\
\hline & Moderate $(\mathrm{n}=48)$ & 8 & 2.4 & 12 & 3.6 & 28 & 8.5 & \\
\hline & $\operatorname{High}(n=268)$ & 27 & 8.2 & 42 & 12.7 & 199 & 60.3 & \\
\hline
\end{tabular}

** Correlation Coefficient is significant at the 0.01 level (2-tailed). Spearman’s rho used to illustrate the strong point of correlation involving 2 numerical ordinal variables.

Moreover, more than two-thirds of the nursing students in the current study are usually and often exposed to work problems. It is expected result because the nursing students are still lacked to knowledge and skills of nursing practice and also, they have a deficiency in social and communicational talents which are essential aptitudes of the nursing staff in 
the healthcare field and particularly with wide range cases in Medical-Surgical Nursing care. Harmoniously with this finding, at Gaziantep University in Turkey, Karadag et al., in 2013 found that the nursing students used to confront many work problems, because, they have insufficient preparation in their clinical training. As well, they verbalized that they faced various clinical training barriers because they could not use the theoretical knowledge they received. Contradicting to this result, Jamshidi et al., in 2016 in Iran, discussed and concluded that the nursing students should be prepared well for clinical training, because, the nursing work is a vital mission and can't tolerate $1 \%$ errors. ${ }^{[34-36]}$ The clinical instructors have to train the nursing students in the simulation lab adequately to teach them how to solve any clinical problems. The instructors should meet the nursing student's knowledge and skills needs and equip them with the art of communication and psychosocial interactions.

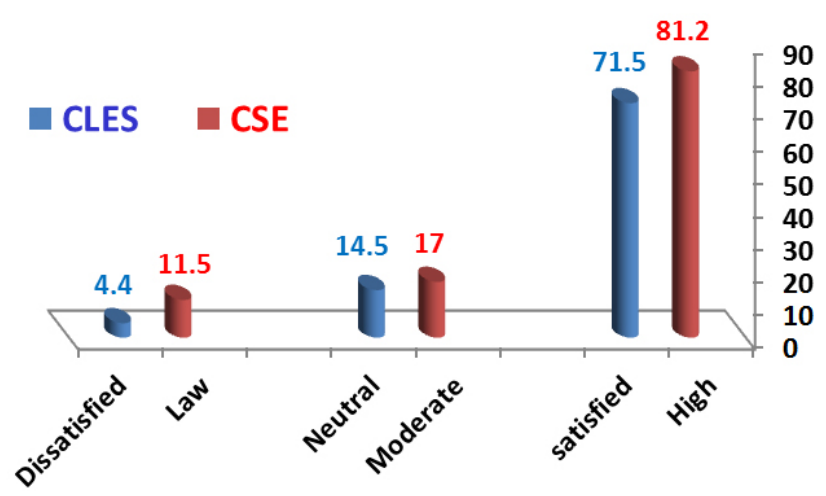

Figure 1. The correlation between nursing student's clinical learning environment satisfaction and their competency self-efficacy as presented by percentages

To answer the first question in the present study, and pertaining to the satisfaction level about clinical learning environment among nursing students, a great part of them (71.5\%) satisfied with their clinical placement with a high mean score (3.6) in all items of clinical learning environment inventory. Matching with the exits result, Papastavrou et al., in 2016 at the University of Cyprus in Aglantzia, Nicosia, found that the nursing students' satisfaction is an essential indicator that linked with academic reforms to improve student's achievements in clinical training. The students have a high satisfaction level regarding the clinical learning environment which is correlated with all constructs of educational approaches and practical activities. Additionally, Lee et al., in 2009 and Papathanasiou in 2014 reported that the nursing student's satisfaction with the clinical placement is considered a significant factor that leads to improvement of health care practices, field belonging, and work motivation. The clinical instructor is a key person to maintain and enhance student's satisfaction toward their clinical training place..$^{[1,7,37]}$ All academic efforts should be directed to keep and improve nursing student's satisfaction about clinical learning environment which is reflected in all components of the quality of patient's care and of course, enhance student's academic success. In the same line, D'Souza et al., in 2014 at College of Nursing, Sultan Qaboos University, Muscat, Sultanate of Oman, found that nursing student's satisfaction with clinical learning environment is a highly significant and have a comparable association with academic and non-academic aspects of clinical training. It is a proper tool to develop nursing student's leadership style, better healthcare activities, and work commitment. There are numerous factors may affect the student's satisfaction level with the clinical learning environment positively or negatively such as student's age, GPA and instructor guidance. ${ }^{[7,38]}$

Opposing to this finding, Shabnum et al., in 2018 in Lahore University, Pakistan, reported in the paragraph of the problem statement of their clinical learning environment that commonly they noticed nursing student's dissatisfaction with their clinical learning environment. The researchers built their observation according to some reasons such as student's feelings of tension in clinical placement, unhelpful ward environment, and negative impression of the instructors. Furthermore, students found difficulty to build supervisory rapport and to receive constructive feedback. ${ }^{[3,39]}$ More or less, we are as nursing educators, and mainly in a vital nursing area like Medical-Surgical Nursing, agreed that, the clinical instructors have the responsibility to tailor all elements of clinical learning environment to be positive, in terms of student's chances in provision of care and clinical decisions, orientation on work routine and policies, and varying of instructor teaching methodology. Preparation of clinical placement with equipment, facilities, guidance, and continuous support should be settled in the curricula and it will be a constructive step for gaining competent nurses in the future.

Concerning to the answering of the second question in the current study, and about competency self-efficacy level as perceived by nursing students, the majority of them (81.2\%) perceived that they have a high level of competency selfefficacy with high mean score (4.1) in all items of competency self-efficacy scale. The current finding indicates that nursing students have capabilities and talents to achieve their targets from the clinical training experiences. Congruent with the current result, Bhandari et al., in 2016 documented that nursing students should have an optimal level of competency self-efficacy because the nursing work can't tolerate any inaccuracy. The high competence self-efficacy that perceived by nursing students is referring to the awareness of their 
competent abilities for achieving their clinical objectives which is a necessary prerequisite with the undergraduates. Strong competency self-efficacy is associated with proficient nursing practice and academic improvement. When nursing students feel high competency self-efficacy, she/he will give skillful patient care without any tension or risks. Their high competency self-efficacy level qualifies them to be criticalthinkers, decision-makers, and clinical managers in difficult work situations. ${ }^{[26,40]}$ Moreover, and fitting to the recent result, Alavi in 2014 in Iran and Zengin et al., in 2014 in Turkey, emphasized that elevated competency self-efficacy with nursing students is a fundamental and crucial potential that motivate them to have the ability for implementing work roles. Self-efficacy is a beneficial trait to forecast nursing students' clinical achievement. Competency self-efficacy can be learned and imitated or acquired by competent clinical instructors. Work loyalty, commitment, and professionalism are features among expert registered nurses who have high self-efficacy level in work performance. With high competency self-efficacy, the nursing students able to manage any conflict and dilemma or challenge in nursing practice which is filled by problems. Competency self-efficacy has rooted in social learning theory which discussed the essential motive such as hunger or thirst and acquired motives such as good behaviors that are representing in proper management and decision making. Additionally, a nurse's job contentment and work motivation are increased by strong competency self-efficacy. ${ }^{[41,42]}$ Nursing students, generally and in Medical-Surgical in particular, should have high competency self-efficacy that gives the feeling of independence, self-control, and self-confidence over work situations and the surrounding environment.

On the other hand, and mismatching with these views, several types of research mentioned that there are some of the nursing students have low competency self-efficacy or have some doubt about their capabilities to achieve clinical goals. They tend to fail in work accomplishment, provide underprivileged nursing services, achieve an unacceptable quality of care and commit many work errors and misbehaviors. Nurses with low or weak competency self-efficacy confront many obstacles in carrying out nursing care. They tend to avoid any situation or procedure that may lead them to failure. Educationally, and in a very foremost department like Medical-Surgical Nursing, focuses on administering a wide range of knowledge and practices basics, weak competency self-efficacy among those nursing students may lead to several unconstructive consequences, such as lack of self-esteem, and poor clinical judgment. In such a case, the nursing students can't deal with clinical problems and unable to manage work responsibilities and accountabilities. ${ }^{[10,40,42]}$ As well,
Farokhzadian et al., in 2015 in Iran found that the greater part of nurses have a weak level of competency self-efficacy during practicing nursing tasks and consequently they failed to employ the evidence-based practice in nursing care. Although all nurses have bachelor educational level in nursing, they have a lower level of competency self-efficacy and they mentioned that they have no guidance or tutorial trials to improve their level of competency self-efficacy in nursing practice. Low level of competency self-efficacy among nursing students, in Medical-Surgical Nursing practice, directs to poor achievement of professional qualifications and accordingly the gap between the knowledge and application will be increased. Furthermore, a low standard of patient care will take place. ${ }^{[10,42,43]}$ Clinical instructors are obliged to allow the nursing students who with low competency self-efficacy to get success on the nursing activities that they had anticipated to fail on it. The nursing students ought to recognize that high competency self-efficacy is a positive sign of proficient care and professional nursing practice. In Clinical Medical-Surgical Nursing courses, the nursing students may have some daily duties and procedures, such as drug or injection administration, wound dressing, burn care, oxygen therapy provision, manage patient bleeding, pre, immediate and post-operative care, Intravenous insertion, Naso-gastric feeding, and blood transfusion. All of those activities necessitate a strong competency self-efficacy, particularly with a nursing student who is still under training and guidance of Medical-Surgical department's clinical training instructors. The educational system of the nursing faculty should recognize, investigate and overcome this debate.

With reference to the answering of the third question in the existing study and as regards the correlation between satisfaction about the clinical learning environment and competency self-efficacy levels among nursing students. The result reveals that there is an obvious parallel correlation between nursing student's satisfaction about the clinical learning environment and their competency self-efficacy levels. The nursing students who reported high scores in satisfaction about the clinical learning environment have high scores in competency self-efficacy and vice-versa. Consequently, a stronger positive correlation is observed between the study variables as perceived by the nursing students. The positive or parallel correlation coefficient among the study variables is significant. It is the most important and exceptional finding of the current study. This finding is going in a line with Herliani et al., in 2018 in Indonesia and Azmoude et al., in 2017 in Iran who clarified that high competency self-efficacy among nursing students is positively correlated with many factors personally and educationally. It parallels with the student's level of comprehension, self-confidence, fruitful communica- 
tion, task performance, and helpful clinical placement. The authors added that the nursing students who have well-built competency self-efficacy, experience elevated satisfaction with all components of the clinical learning environment. Therefore, high competency self-efficacy is positively linked with strong satisfaction with the clinical placement aspects. Professional nursing students with high competency selfefficacy satisfied with the clinical work atmosphere and felt familiar with all circumstances in the clinical site. Further, the students recognized the importance of their competency self-efficacy in practice and then tailor all components of the clinical learning environment to be fit their targets. Their elevated level of competency self-efficacy is positively matching with their high satisfaction level about the clinical learning environment which includes: educational methodology in clinical training, instructor coaching, nursing staff supervision, peer relationship, client's communication, routine care rules, and academic grading. ${ }^{[1,44,45]}$ It is essential to determine all factors that parallel and enhance nursing students' competency self-efficacy because strong competency self-efficacy is the hope of any nursing program, MedicalSurgical Nursing and Nursing Education in general. This positive correlation is expected and is a perfect sign for all our nursing students plus it is supporting the study hypothesis. Therefore, well planning and organization of the clinical placement will be an effective way to increase nursing student's competency self-efficacy in their clinical training, predominantly, in a fundamental field like Medical-Surgical Nursing.

Also, and compatible to the earlier views, in Egypt, $\mathrm{Al} \mathrm{Se}$ baee et al, in 2017 discovered that a greater portion of the nursing students have high satisfaction level about clinical learning environment and there is statistically noteworthy corresponding relationship between it and students' academic performance in nursing courses, particularly, in clinical part. High level of satisfaction about clinical learning environment is matching with a strong level of clinical competency self-efficacy and educational effectiveness among nursing students. Thus the elevated level of satisfaction about clinical learning environment and high competency self-efficacy are harmonizing with nursing students' academic success. ${ }^{[36,45]}$ The current research variables should be considered and encouraged among nursing students by appropriate educational planning for major clinical courses like Medical-Surgical Nursing. Clinical instructors ought to be aware by and investigate these variables and prepare clinical placement with innovative teaching approaches to increase its levels with undergraduates.

Contradictory, to the recent results, in Iran, Jamshidi et al., in 2016, Yazdannik et al., in 2012 and Nayeri et al., in 2006 reported that there are numerous researches have been conducted on satisfaction about clinical placement and competency self-efficacy among nursing students. Some studies found that most of the nursing students exposed to a lot of strains and threats in the clinical area. Subsequently, they frequently stated dissatisfaction with their clinical learning environment; even they have strong competency self-efficacy. Other nursing students described themselves as "vulnerable students" or they have "inferiority complex" because they still students and have insufficient knowledge and skills in clinical training. They have very limited satisfaction toward clinical learning environment, but they do their best in practice and have elevated competency self-efficacy in patient' care. Likewise, nursing students confronted many difficulties in clinical training which lead to their frustration with the clinical learning environment. Students may have wonderful competences with strong competency selfefficacy; but, too, they may have no clinical learning environment satisfaction. ${ }^{[36,46,47]}$ This finding is contradicting the current result. It showed that maybe there is a reverse association between satisfaction about the clinical learning environment and competency self-efficacy. Therefore, the current researchers viewed that the negative or positive correlation in between satisfaction about the clinical learning environment and competency self-efficacy is dependent on the clinical instructor's efforts and curriculum plan for meeting the nursing student's physical and psychological needs in clinical placement. Besides, the clinical instructors should encourage students' trials to do difficult nursing tasks in a successful manner which tends to increase the student's competency self-efficacy.

\section{CONCLUSION AND RECOMMENDATIONS}

According to the current finding, undergraduate nursing students in Medical-Surgical Nursing department at the Faculty of Nursing, Alexandria University, have a high level of satisfaction about the clinical learning environment with all components of the clinical placement. As well, they have a high competency self-efficacy level in all nursing activities and tasks in clinical training. Further, there is an obvious parallel correlation between nursing student's satisfaction about the clinical learning environment and their competency self-efficacy level. The nursing students who reported high scores in satisfaction about the clinical learning environment have high scores in competency self-efficacy and vice-versa. The positive or parallel correlation coefficient among satisfaction about the clinical learning environment and competency self-efficacy variables among nursing students is significant. Thus, it was recommended that nursing students should receive a detailed and accurate orientation before entering the 
clinical setting. Adequate, accurate and planned preparations should be settled for the clinical placement and the clinical training in Medical-Surgical Nursing curricula and clinical practice. The clinical instructors should encourage students' trials to do difficult nursing tasks in a successful manner which tends to increase the student's competency self-efficacy. Satisfaction about the clinical learning environment and competency self-efficacy among nursing students should be investigated by the clinical instructors at the beginning of the clinical experience. They are two important variables with nursing students and essential concepts that should be incorporated into the Medical-Surgical Nursing curricula. Regular seminars and meeting should be held with the clinical instructors to discuss how to improve the factors

\section{REFERENCES}

[1] Papastavrou E, Dimitriadou M, Tsangari H, et al. Nursing students' satisfaction of the clinical learning environment: a research study. BMC Nursing. 2016; 15-44. PMid:27436992 https://doi.org/ $10.1186 / \mathrm{s} 12912-016-0164-4$

[2] European Parliament. Directive 2013/55/EU of the European Parliament and of the council of 20 November 2013 amending Directive 2005/36/EC on the recognition of professional qualifications and Regulation (EU) No 1024/2012 on administrative cooperation through the Internal Mark. Off J Eur Union. 2013; 132-170.

[3] D’Souza MS, Karkada SN, Parahoo K, et al. Perception of and satisfaction with the clinical learning environmentamong nursing students. Nurse Educ Today. 2015; 35: 833-40. PMid:25729010 https://doi.org/10.1016/j.nedt.2015.02.005

[4] Berntsen K, Bjrk IT, Brynildsen C. Nursing Students' Clinical learning environmentin Norwegian Nursing Homes: Lack of Innovative Teaching and Learning Strategies. Open Journal of Nursing. 2017; 7 : 949-961. https://doi.org/10.4236/ojn.2017.78070

[5] Berntsen K, Bjørk IT. Nursing Students' Perceptions of the Clinical learning environmentin Nursing Homes. Journal of Nursing Education. 2010; 49: 17-22. PMid:19731888 https ://doi .org/10. 392 8/01484834-20090828-06

[6] Sezer H. How should clinical education be in nursing education? J Nurs Res Pract. 2018; 2(1): 15.

[7] Papathanasiou LV, Tsaras K, Sarafis P. Views and perceptions of nursing students on their clinical learning environment: Teaching and learning. Nurse Education Today. 2014; 34: 57-60. PMid:23481172 https://doi.org/10.1016/j.nedt.2013.02.007

[8] Academy of medical-Surgical Nurses. What is Medical-Surgical Nursing? 2018. Available from: https : //www .amsn .org/pract ice-resources/what-medical-surgical-nursing

[9] Flott EA, Linden L. The clinical learning environmentin nursing education: a concept analysis. Journal of Advanced Nursing. 2015; 72(3): 501-513. PMid:26648579 https ://doi.org/10.1111/ja n. 12861

[10] Academy of medical-Surgical Nurses. Scope and Standards of Medical-Surgical Nursing Practice, 6th Edition. Academy of medical-Surgical Nurses. 2018; 5-24. Available from: that may strengthen satisfaction about clinical learning environment satisfaction and competency self-efficacy in clinical training among nursing students. Further researches are required to investigate the factors affecting clinical learning environment and competency self-efficacy among nursing students in their clinical placement. As well, another research is necessary about; developing an educational program about student's competency self-efficacy to guide Medical-Surgical Nursing instructors in clinical training. Additionally, replication of the current study is needed, but in more than one nursing faculty and with different tools (assessment of skills and knowledge, not the assessment of attitudes only).

\section{CONFLiCTS OF INTEREST Disclosure}

The authors declare that they have no conflicts of interest.
https://www.amsn.org/sites/default/files/.../AMS

N-Scope-Standards-MS-Nursing ·pdf

[11] Chan D. Development of the clinical learning environment inventory: using the theoretical framework of learning environment studies to assess nursing students' perceptions of the hospital as a learning environment. Journal of Nursing Education. 2002; 41(2): 69-75. https://doi.org/10.3928/0148-4834-20020201-06

[12] Kirkman TR. High fidelity simulation effectiveness in nursing students' transfer of learning. International Journal of Nursing Education Scholarship. 2013; 10: 1-6. PMid:23934438 https ://doi .org/10 .1515/ijnes-2012-0009

[13] Park MY. Clinical learning environmentary S.R., McMillan M.A., Murphy L., Conway J.F. Griffiths S.K. Practice-based simulation model: a curriculum innovation to enhance the critical thinking skills of nursing students. Australian Journal of Advanced Nursing. 2013; 30: 41-51.

[14] Babenko-Mould Y, Laschinger HK. Effects of in civility in clinical practice settings on nursing student burnout. International Journal of Nursing Education Scholarship11. 2014; 1: 145-154. PMid:25367690 https://doi.org/10.1515/ijnes-2014-002 3

[15] Welding NM. Creating a nursing residency: decrease turnover and increase clinical competence. Med-Surg Nursing. 2011; 20(1): 37-40.

[16] Sand-Jecklin K. Assessing nursing student perceptions of the clinical learning environment: refinement and testing of the SECEE inventory. Journal of Nursing Measurement. 2009; 17(3): 232-246. https://doi.org/10.1891/1061-3749.17.3.232

[17] O’Mara L, McDonald J, Gillespie M, et al. Challenging clinical learning environments: experiences of undergraduate nursing students. Nurse Education in Practice. 2014; 14: 208-213. PMid:24063792 https : //doi.org/10.1016/j.nepr.2013.08.012

[18] Chuan OL, Barnett T. Student, tutor and staff nurse perceptions of the clinical learning environment. Nurse Education in Practice. 2012; 12(4): 192-197. PMid:22277167 https ://doi.org/10.1016/j . nepr.2012.01.003

[19] Wilkins S, Balakrishnan MS. Assessing student satisfaction in transnational higher education. International Journal of Educational Management. 2013; 146-153. 
[20] Weerasinghe IM, Fernando LS. Students' Satisfaction in Higher Education Literature Review. American Journal of Educational Research. 2017; 5(5): 533-539.

[21] Sundler AJ, Björk M, Bisholt B, et al. Student nurses' experiences of the clinical learning environmentin relation to the organization of supervision: a questionnaire survey. Nurse Educ Today. 2014; 34: 661-666. PMid:23850574 https://doi.org/10.1016/j.ne dt. 2013.06.023

[22] Saarikoski M, Kaila P, Lambrinou E, et al. Students' experiences of cooperation with nurse teacher during their clinical placements: an empirical study in a Western European context. Nurse Educ Pract. 2013; 13: 78-82. PMid:22902569 https ://doi .org/10.1016/j . nepr.2012.07.013

[23] Gudayu TW, Badi MB, Asaye MM. Self-Efficacy, Learner Satisfaction, and Associated Factors of Simulation Based Education among Midwifery Students: A Cross-Sectional Study. Hindawi Publishing Corporation 2015, Articlinical learning environment. https://doi.org/10.1155/2015/346182

[24] Bandura A. Self-efficacy: Academic Press. Encyclopedia of mental health. New York; 1998. Available from: http://www.des. emory . edu/mfp/BanEncy.html

[25] Bandura A. The explanatory and predictive scope of self efficacy theory. Journal of Social and Clinical Psychology. 1986; 4: 359-373 https://doi.org/10.1521/jscp.1986.4.3.359

[26] Bhandari P, Pareek P, Vashisht S, et al. Nursing Competency Self Efficacy (NCOMPETENCY SELF-EFFICACY) Scale for Outgoing Nursing Students. IOSR Journal of Nursing and Health Science. 2016; 5(1): 56-63.

[27] Hughes A, Galbraith D, White D. Perceived Competence: A Common Core for Self-Efficacy and Self-Concept? Journal of Personality Assessment. 2011; 93(3): 278-289. PMid:21516587 https : //doi.org/10.1080/00223891.2011.559390

[28] Al Sebaee HA, Abdel Aziz EM, Mohamed NT. Relationship between Nursing Students' Clinical Placement Satisfaction, Academic Self-Efficacy and Achievement. IOSR Journal of Nursing and Health Science. 2017; 6(2): 101-112. https://doi.org/10.9790/1959 $-060203101112$

[29] Chan D. Development of the clinical learning environmentinventory: Using the theoretical framework of learning environment studies to assess nursing students' perceptions of the hospital as a learning environment. The Journal of Nursing Education. 2002; 41(2): 69-75. https ://doi.org/10.3928/0148-4834-20020201-06

[30] Chan DSK. Validation of the clinical learning environmentinventory. Western Journal of Nursing Research. 2003; 25(5): 519-532. PMid:12955969 https://doi.org/10.1177/01939459032531 61

[31] Kennedy E. The Nursing Competence Self-Efficacy Scale (NCOMPETENCY SELF-EFFICACYS): An Instrument Development and Psychometric Assessment Study. Published doctoral thesis. DALHOUSIE UNIVERSITY, SCHOOL OF NURSING. 2013; 52-87.

[32] Abdel El-Halem GE, El Hawashy ZI, Gamal El-Dein AA, et al. Undergraduate Male Nursing students' Perception about the Image of the Nursing Profession. Journal of American Science. 2011; 7(3): 614-23.

[33] Gaber M, Mostafa M. Comparison of Nursing Students' perceptions about Male Nursing among Zagazig University in Egypt and Shaqra University in Saudi Arabia. Life Science Journal. 2013; 10(4).
[34] Bigbee J, Mixon D. Recruitment and Retention of Rural Nursing Students: A Retrospective Study. International Electronic Journal of Rural and Remote Health Research, Education, Practice and Policy. 2013; 1-10.

[35] Karadag G, Kayaaslan H, Kilic S, et al. Difficulties Encountered by Nursing Students in Practices and Their Views about Nurses. ResearchGate. 2013; 12(6): 1. https://doi.org/10.5455/pmb. $1-1353569323$

[36] Jamshidi J, Molazem Z, Sharif F, et al. The Challenges of Nursing Students in the Clinical Learning Environment: A Qualitative Study. Scientific World Journal. 2016. PMid:27366787 https : //doi.org/10.1155/2016/1846178

[37] Lee CY, White B, Hong YM. Comparison of the clinical practice satisfaction of nursing students in Korea and the USA. Nurs Heal Sci. 2009; 11: 10-16. PMid:19298303 https://doi.org/10.1111/j . 1442-2018.2008.00413.x

[38] D'Souza MS, Karkada SN, Parahoo K, et al. Perception of and satisfaction with the clinical learning environmentamong nursing students. Nurse Education Today. 2015; 35(6): 833-840. PMid:25729010 https://doi.org/10.1016/j.nedt.2015.02.005

[39] Shabnum S, Hussain M, Majeed I, et al. Nursing Students' Satisfaction with Clinical Learning Environment. International Journal of Graduate Research and Review. 2018; 4(1): 58-63.

[40] Stump GS, Husman J, Brem SK. The Nursing Student Self-Efficacy Scale: development using item response theory. Nurs Res. 2012; 61(3): 149-58. PMid:22551989 https://doi .org/10.1097/NNR . Ob013e318253a750

[41] Alavi NM. Self-Efficacy in Nursing Students. Nurs Midwifery Stud. 2014; 3(4): e25881. https://doi.org/10.17795/nmsjourna 125881

[42] Zengin N, Pinar R, Akinci AC, et al. Psychometric properties of the self-efficacy for clinical evaluation scale in Turkish nursing students. J Clin Nurs. 2014; 23(7-8): 976-84. PMid:23876212 https://doi.org/10.1111/jocn. 12257

[43] Farokhzadian J, Khajouei R, Ahmadian L. Evaluating factors associated with implementing evidence-based practice in nursing. Journal of Evaluation in Clinical Practice. 2015; 21(6): 1107-1113. PMid:26563564 https://doi.org/10.1111/jep. 12480

[44] Herliani Y, Harun H, Setyawati A, et al. Self-Efficacy and the Competency of Nursing Students toward the Implementation of Evidence-Based Practice. Jurnal Ners. 2018; 13(1): 50-56. https : //doi.org/10.20473/jn.v13i1.6359

[45] Azmoude E, Farkhondeh F, Ahour M, et al. Practice and SelfEfficacy in Evidence-Based Practice among Midwives in East Iran. Sultan Qaboos University Medical Journal. 2016; 17(1): e66-e73. PMid:28417031 https://doi.org/10.18295/squmj . 2016.17 .01 .012

[46] Yazdannik AZ, Yekta P, Soltani A. Nursing professional identity: an infant or one with Alzheimer. Iranian Journal of Nursing and Midwifery Research, 2012; 17(2): 1. Articlinical Learning Environment. 2012.

[47] Nayeri ND, Nazari AA, Salsali M, et al. Iranian staff nurses' views of their productivity and management factors improving and impeding it: a qualitative study. Nursing and Health Sciences. 2006; 8(1): 5156. PMid:16451429 https://doi .org/10.1111/j.1442-2018. $2006.00254 . x$ 